\title{
Application of Plackett-Burman and central composite designs for screening and optimization of factor influencing the chromatographic conditions of HPTLC method for quantification of efonidipine hydrochloride
}

\author{
Suraj R. Chaudhari (1) and Atul A. Shirkhedkar
}

\begin{abstract}
We report here an analytical method for expeditious estimation of efonidipine hydrochloride in tablet formulation with statistical screening and optimization designs using NP-HPTLC. TLC silica gel $60 \mathrm{~F}_{254}$ aluminum plates and ethyl acetate to dichloromethane to triethylamine $(3: 2: 0.5 \mathrm{v} / \mathrm{V})$ were chosen for chromatographic separation of efonidipine hydrochloride. The $R_{f}$ value for efonidipine hydrochloride turned out to be $0.35 \pm 0.25$ and quantitative evaluation was done at $251 \mathrm{~nm}$. Plackett-Burman and face-centered central composite design (CCD) were used to obtain the most peak area and well-resolved compact band with an adequate retention factor of efonidipine hydrochloride. PlackettBurman design at two-level with six independent variables has been employed for screening of prominent factors that affect the responses. The prominent factors have been selected and are optimized through face-centered CCD. The results obtained from face-centered CCD showed that most peak area can be obtained with development distance $8.50 \mathrm{~cm}$ and chamber saturation $17 \mathrm{~min}$. Furthermore, the current NP-HPTLC investigation has been validated according to the $\mathrm{ICH}$ guidelines for accuracy, precision, sensitivity, robustness, ruggedness, and specificity. The detection and quantification limit was found that $10.41 \mathrm{ng}$ and $31.57 \mathrm{ng}$, suggesting that the analysis could be accurately and precisely detected the analyte up to nanogram quantity. The current NP-HPTLC investigation is rugged, accurate, and highly sensitive and could be used for routine analysis of efonidipine hydrochloride.
\end{abstract}

Keywords: Calcium channel blocker, Efonidipine hydrochloride, HPTLC, Plackett-Burman design, Response surface methodology

\section{Introduction}

Efonidipine hydrochloride (EFH) is a dihydropyridine class of the calcium channel blocker chemically 2-[benzyl(pheny1)amino] ethyl 5-(5,5-dimethyl-2-oxo-1,3,2lambda5-dioxaph osphinan -2-yl)-2,6-dimethyl-4-(3-nitrophenyl)-1,4-dihydro

\footnotetext{
* Correspondence: chaudharisuraj72@gmail.com

Central Instrumental Facility (CIF), Department of Pharmaceutical Chemistry, R. C. Patel Institute of Pharmaceutical Education and Research, Shirpur, Maharashtra 425405, India
}

\section{Springer Open}

pyridine-3-carboxylate hydrochloride. It is an antihypertensive and antianginal drug with dihydropyridine ring in its chemical structure Fig. 1. EFH effectively blocks $\mathrm{Ca}^{2+}$ channels of types $\mathrm{L}$ and $\mathrm{T}$ and has a better clinical profile (Tanaka and Shigenobu 2002). EFH has an excellent pharmacological profile, because it has a phosphate moiety in the 5th position of the dihydropyridine ring which makes it different from other dihydropyridine agents (Masuda et al. 1995; Masumiya et al. 1997; Masumiya et al. 2000).
(0) The Author(s). 2020 Open Access This article is licensed under a Creative Commons Attribution 4.0 International License, which permits use, sharing, adaptation, distribution and reproduction in any medium or format, as long as you give appropriate credit to the original author(s) and the source, provide a link to the Creative Commons licence, and indicate if changes were made. The images or other third party material in this article are included in the article's Creative Commons licence, unless indicated otherwise in a credit line to the material. If material is not included in the article's Creative Commons licence and your intended use is not permitted by statutory regulation or exceeds the permitted use, you will need to obtain permission directly from the copyright holder. To view a copy of this licence, visit http://creativecommons.org/licenses/by/4.0/. 


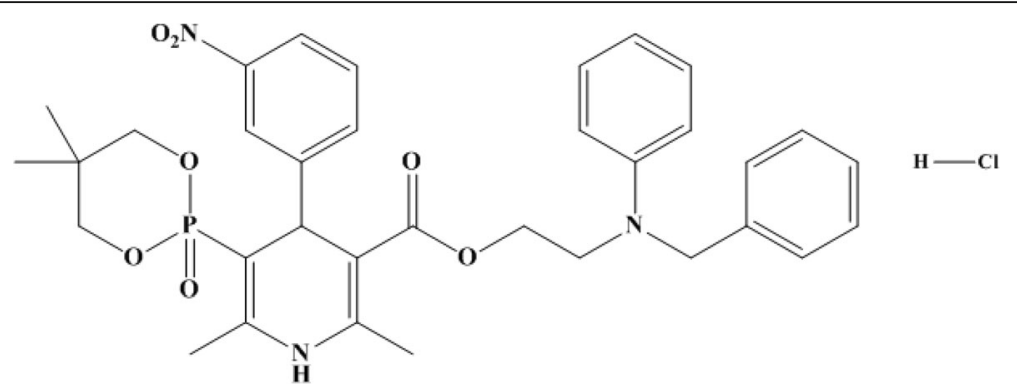

Fig. 1 Chemical structure of efonidipine hydrochloride

EFH blocks $\mathrm{Ca}^{2+}$ channels of types $\mathrm{L}$ and $\mathrm{T}$ as a result of that vasodilation and decreased automaticity of the heart and causes negative chronotropic effect and lower the heart rate (Tanaka and Shigenobu 2002).

From the other instrumental techniques of pharmaceutical analysis, high-performance thin-layer chromatography (HPTLC) is the most significant technique because the advances in the stationary phase and the commencement of densitometric detection are increasingly being used nowadays in the area of drug analysis. HPTLC is a more efficient tool over liquid chromatography because the separation of several samples in parallel on the same plate allowing high-throughput and rapid low-cost analysis and also a small amount of organic solvents are needed and which somewhat reduces the disposal of hazardous organic solvents (Shewiyo et al. 2012). While developing the method for pharmaceuticals using HPTLC, the analyst has to optimize some controllable variables including activation of the plate, chamber saturation, volume and composition of the mobile phase, detection wavelength, type of stationary phase, and type of detector. The "trial and error" strategy has been used for long years to optimize these controllable variables; this approach comprises of changing one variable at a time whereas other variables have to maintain steady to get efficient separation of pharmaceuticals. Moreover, this traditional approach can consume a lot of time and money to optimize the robust conditions for the analysis of pharmaceuticals.

Therefore, the experimental designs are extensively used from the past few years for optimization of analytical methods because it requires less time, efforts, and resources than the traditional approach. It is a stunning tool and enables a simultaneous evaluation of several variables at multiple levels in a limited number of experiments. The two types of experimental design are used for the optimization of method, i.e., screening and optimization design (response surface methodology). The screening design is basically comprised of full factorial design, factorial design, and Plackett-Burman design (PBD) which are used to identify the most crucial independent variable influencing response. Response surface methodology (RSM) consisting of central composite design (CCD), Box-Behnken design, and
Doehlert design is employed for the optimization of the most crucial independent variable and to identify the optimum level of each factor (Müller et al. 2020; M. Cavazzuti 2013; Tauler et al. 2009).

PBD is a type of two-level fraction factorial screening design. The most important aspect of this design is combining different combinations of the independent variables with a variable level. Through PBD, maximum $\mathrm{N}-1$ independent variables can be examined, where $N$ is a multiple of 4. PBD is a very efficient screening design for the evaluation of independent variables with very few experimental runs which result in the preservation of chemicals, times, and the most important saving of human resources (Ahuja et al. 2004).

A review of the literature revealed that few analytical methods for quantification of EFH have been reported. The HPLC method for determination of EFH (Kumar et al. 2017), LC-MS/MS, and chiral LC-MS/MS methods have been reported for the determination of EFH in human plasma (Liu et al. 2015; Liu et al. 2016).

To date, no HPTLC method has been studied to quantify of EFH in tablet formulation and due to the lack of reports in the literature for the investigation of the impact of independent variables of the HPTLC method on the responses using PBD and CCD. Therefore, the scientific novelty of the proposed work is to explore PBD and RSM experimental design approach for screening and optimization of independent variables and validation of a method for quantification of EFH in tablet formulation using normal phase (NP)-HPTLC method.

\section{Materials and methods} Instrumentation

A CAMAG Linomat 5 applicator with sample syringe of $100 \mu \mathrm{L}$ (Hamilton, Bonaduz, Switzerland) for sample application under a gentle stream of nitrogen for immediate evaporation and evaluation of thin-layer chromatography (TLC) plates were done using CAMAG TLC 3 scanner, and data analysis was performed using winCATS version 1.3.0-Planar Chromatography Manager software (CAMAG, Muttenz, Switzerland). The HPTLC system facilitates with deuterium, and halogen-tungsten lamp and measurement 
were performed using absorbance/reflectance mode. The slit dimensions of TLC 3 scanner were set at $6.00 \times 0.45$ $\mathrm{mm}$, data resolution was $100 \mu \mathrm{m} / \mathrm{step}$, and scanning speed was kept at $20 \mathrm{~mm} / \mathrm{s}$. A twin-trough chamber was used for the development of TLC plates. Shimadzu AUX-120 analytical balance was used for weighing operations.

\section{Materials and chemicals}

HPLC grade dichloromethane, ethyl acetate, triethylamine, and all other solvents were purchased from Merck Life Science, Mumbai, India, and Avantor Performance Materials, Thane, India. TLC silica gel $60 \mathrm{~F}_{254}$ aluminum sheets $(20 \times 20 \mathrm{~cm})$ were purchased from Merck, Darmstadt, Germany. EFH of pharmaceutical grade was acquired as a gift sample from Zuventus Healthcare Ltd. Mumbai, India. Efnocar- 40 was labeled to contain $40 \mathrm{mg}$ EFH per tablet, a marketed product of Zuventus Healthcare Ltd. Mumbai, India.

\section{Preparation of standard solution}

A stock solution of EFH $(1 \mathrm{mg} / \mathrm{mL})$ was prepared by transferring the accurately weighed $10 \mathrm{mg}$ of $\mathrm{EFH}$ in 10 $\mathrm{mL}$ of methanol, and the solution was stored at $5{ }^{\circ} \mathrm{C}$ up to the time of further dilution and analysis. The stability of the standard solution was accomplished under optimized conditions.

\section{Chromatographic procedure}

All measurements were executed on TLC silica gel 60 $\mathrm{F}_{254}$ aluminum plates. Before use, each plate was cut into $10 \times 10 \mathrm{~cm}$ and prewashed with methanol. The standard and sample solution of EFH $(\mu \mathrm{L})$ were applied to the TLC plate, $15 \mathrm{~mm}$ from the bottom and $15 \mathrm{~mm}$ from the side edges, in the form of bands ( $6 \mathrm{~mm}$ bandwidth). Five milliliters of the mobile phase consisted of ethyl acetate to dichloromethane to triethylamine $(3.0: 2.0: 0.5 \mathrm{v} / \mathrm{v})$ was poured into the twin-trough chamber. The chamber was saturated with an optimized mobile phase for $17 \mathrm{~min}$ at room temperature $\left(28 \pm 2{ }^{\circ} \mathrm{C}\right)$. The linear ascending plate development was achieved until a migration distance of $8.5 \mathrm{~cm}$ from the origin. Subsequently to development, the plates were dried in air for almost a minute. The quantification of analytes was done at $251 \mathrm{~nm}$ using absorbance/reflectance mode, and the rest of the data analysis was carried out using winCATS software.

\section{Statistical tool}

Minitab $^{\bullet}$ 17.1.0, USA software was used for developing PBD for the screening of independent variables and Design Expert (Version 7.0.0), Stat-Ease, Inc. Minneapolis, $\mathrm{MN}$, 55413, for designing a CCD and RSM for optimization of independent variables.

\section{Experimental}

Experimental design and statistical analysis for the optimization of chromatographic conditions

For estimation of EFH with high specificity and selectivity in pure form and pharmaceutical preparation, the developed TLC method was optimized to obtain maximum peak area and that would give a dense and well-resolved compact band with an adequate retention factor $\left(\mathrm{R}_{f}\right)$ for EFH which was desired. Therefore, the present method was subjected to PBD for a screening of independent variables and optimization of the significant independent variables using RSM.

\section{Plackett-Burman design screening of independent variables}

The PBD is an efficient screening design to identify the crucial variables among a large number of variables that ultimately affect the results. PBD was utilized to determine the significant independent variable that affects the peak area and $R_{f}$. The independent variables (factors) selected for PBD were wavelength, saturation time, the volume of dichloromethane (DCM), volume of triethylamine, development distance, and activation of the plate and were investigated to identify the significant factor for the peak area and $\mathrm{R}_{f}$ chosen as responses with a confidence level of all intervals at $95 \%$. The level of independent variables employed in PBD is tabulated in Table 1. In the proposed work, a total of 12 experimental runs was obtained using Minitab $^{\bullet}$ 17.1.0 to analyze six factors and their effect on responses. One and all factors were studied at two levels, i.e., for low level -1 and high level +1 . Experimental runs of PBD are depicted in Table 2. The PBD based on a firstorder polynomial model for mathematical modeling which was used is shown in equation (1):

$$
Y=\beta_{0}+\sum \beta i X i
$$

where $Y$ is the responses (peak area and retention factor), $\beta_{0}$ is the model intercept, $\beta i$ is a linear coefficient, and $X i$ is the level of independent variables (Naveena et al. 2005; Vanaja and Shobha Rani 2007). The independent

Table 1 Level of independent variables selected in PlackettBurman design for screening the independent variables

\begin{tabular}{lllll}
\hline Sr. & Independent variables & Unit & \multicolumn{2}{l}{ Experimental value } \\
\cline { 4 - 5 } No. & & & Low (- 1) & High (+ 1) \\
\hline 1 & Wavelength & $\mathrm{nm}$ & 248 & 254 \\
2 & Saturation time & $\mathrm{min}$ & 15 & 25 \\
3 & Volume of dichloromethane & $\mathrm{mL}$ & 1.5 & 2.5 \\
4 & Volume of triethylamine & $\mathrm{mL}$ & 0.3 & 0.7 \\
5 & Development distance & $\mathrm{cm}$ & 7.5 & 8.5 \\
6 & Activation of plate & $\mathrm{min}$ & 8.0 & 12 \\
\hline
\end{tabular}


Table 2 Plackett-Burman design experimental runs for screening the significant independent variables affecting on the responses

\begin{tabular}{|c|c|c|c|c|c|c|c|c|}
\hline $\begin{array}{l}\text { Run } \\
\text { order }\end{array}$ & Wavelength & $\begin{array}{l}\text { Saturation } \\
\text { time }\end{array}$ & $\begin{array}{l}\text { Volume of } \\
\text { DCM }\end{array}$ & $\begin{array}{l}\text { Volume of } \\
\text { triethylamine }\end{array}$ & $\begin{array}{l}\text { Development } \\
\text { distance }\end{array}$ & $\begin{array}{l}\text { Activation of } \\
\text { plate }\end{array}$ & $\begin{array}{l}\text { Peak } \\
\text { area }\end{array}$ & $\begin{array}{l}\text { Retention } \\
\text { factor }\end{array}$ \\
\hline 1 & 1 & 1 & -1 & 1 & -1 & -1 & 4985.45 & 0.77 \\
\hline 2 & -1 & -1 & -1 & -1 & -1 & -1 & 6736.95 & 0.58 \\
\hline 3 & 1 & -1 & 1 & 1 & -1 & 1 & 5383.96 & 0.52 \\
\hline 4 & -1 & 1 & 1 & -1 & 1 & -1 & 5565.23 & 0.5 \\
\hline 5 & 1 & -1 & 1 & -1 & -1 & -1 & 5954.12 & 0.46 \\
\hline 6 & -1 & -1 & -1 & 1 & 1 & 1 & 9045.56 & 0.43 \\
\hline 7 & -1 & 1 & 1 & 1 & -1 & 1 & 4005.6 & 0.49 \\
\hline 8 & 1 & -1 & -1 & -1 & 1 & 1 & 8195.95 & 0.48 \\
\hline 9 & 1 & 1 & 1 & -1 & 1 & 1 & 7902.53 & 0.47 \\
\hline 10 & -1 & -1 & 1 & 1 & 1 & -1 & 9265.45 & 0.55 \\
\hline 11 & -1 & 1 & -1 & -1 & -1 & 1 & 4601.98 & 0.45 \\
\hline 12 & 1 & 1 & -1 & 1 & 1 & -1 & 8315.76 & 0.46 \\
\hline
\end{tabular}

variables with probability value ( $p$ value $<0.05$ ), i.e., more than $95 \%$ confidence level of all intervals, are thoughtabout to have a significant effect on peak area and $\mathrm{R}_{f}$ and by using CCD and RSM, the significant independent variables are optimized. The above experiment was performed using the concentration of $1000 \mathrm{ng} / \mathrm{band}$.

\section{Optimization of HPTLC conditions using face-centered CCD and RSM}

As a consequence obtained after performing PBD for a screening of independent variables, the two most influential significant independent variables were selected for further optimization and to point out the ideal value of each independent variable that would give maximum peak area of EFH. Hence, in the proposed work, an RSM using a 2-factor, 3-level face-centered CCD was applied to optimize and analyze the variables of NP-HPTLC chromatographic separation condition. The two major significant independent variables selected from PBD affecting the response namely development distance $\left(X_{1}\right)$ and saturation time $\left(X_{2}\right)$ were selected and investigated at three different coded levels as 7.5, 8.0, and 8.5 for $X_{1}$ and 15,20 , and 25 for $X_{2}$. Peak area $(Y)$ was picked from PBD as a dependent response variable to be optimized, and the goal was to set to obtain maximum peak area. Thirteen experimental runs were obtained from the face-centered CCD matrix generated from the Design Expert $^{\circ}$ Version 7.0.0 (State-Ease, Inc., Minneapolis, MN) consisting 8 non-center points and 5 center points as shown in Table 3. The impact of each independent variable on responses and model competency was reviewed using analysis of variance (ANOVA) respectively with Fisher's statistical analysis and $p$ value. Besides, the area of the peak was examined by a secondorder polynomial equation and the data fitted by a multiple regression procedure (Dinç-Zor et al. 2020;
Priyadharshini and Bakthavatsalam 2016; Imam et al. 2014; Varshosaz et al. 2010). The statistical relationship between the peak area $(Y)$ to the selected independent variables $X_{1}$ and $X_{2}$ is shown by the following quadratic polynomial equation:

$$
Y=\beta_{0}+\beta_{1} X_{1}+\beta_{2} X_{2}+\beta_{12} X_{1} X_{2}+\beta_{11} X_{1}^{2}+\beta_{22} X_{2}^{2}
$$

where $Y$ is the measure response (peak area), $X_{1}$ and $X_{2}$ are significant independent variables, $\beta_{1}$ and $\beta_{2}$ are the linear regression coefficients, $\beta_{12}$ is the interactive regression coefficient, and $\beta_{0}$ is a constant term. Further, to get maximum peak area, RSM was taken into consideration to analyze the effect of a significant independent variable on response. At the last, the maximum peak area was tradedoff through a graphical optimization process.

\section{Calibration curve of EFH}

Calibration solutions were made in the concentration range of $30-180 \mu \mathrm{g} / \mathrm{mL}$ for $\mathrm{EFH}$ through appropriate dilutions of a stock standard solution. From the resulting solution, a fixed volume of $10 \mu \mathrm{L}$ solution was applied on NPTLC plates in the form of bands to get final concentrations of EFH. The plates were developed using an optimized mobile phase. To check the linearity in the abovestated concentration range, samples were applied six times per concentration and peak area values were recorded. Eventually, the calibration curve was developed by plotting the analyte concentrations against the peak area.

\section{Validation of method}

The present work was validated for accuracy, precision, sensitivity (limit of detection and limit of quantification), ruggedness, robustness, and selectivity considered as the requisite parameters to make sure of the validation of 
Table 3 Face-centered CCD matrix with two independent variables studied accompanied by results marked

\begin{tabular}{llll}
\hline Runs & $\begin{array}{l}\text { Development distance }(\mathbf{m m}) \\
\left(\boldsymbol{X}_{\mathbf{1}}\right)\end{array}$ & $\begin{array}{l}\text { Saturation time }(\boldsymbol{m i n}) \\
\left(\boldsymbol{X}_{\mathbf{2}}\right)\end{array}$ & \begin{tabular}{c} 
Peak area \\
\hline 1
\end{tabular} \\
\hline 8.0 & 25 & 4526.56 \\
2 & 8.5 & 20 & 6512.32 \\
3 & 7.5 & 25 & 5264.65 \\
4 & 8.0 & 20 & 6865.48 \\
5 & 8.0 & 20 & 6795.53 \\
6 & 8.0 & 20 & 6656.69 \\
7 & 8.0 & 20 & 6845.12 \\
8 & 7.5 & 15 & 5156.98 \\
9 & 7.5 & 20 & 5951.18 \\
10 & 8.5 & 25 & 4156.69 \\
11 & 8.5 & 15 & 6965.74 \\
12 & 8.0 & 20 & 6685.48 \\
13 & 8.0 & 15 & 5985.56 \\
\hline
\end{tabular}

the analytical method. NP-HPTLC method efficiency has been assessed using International Conference of Harmonisation 2005).

\section{Accuracy}

The accuracy of the NP-HPTLC method was investigated by calculating the percentage (\%) recovery of EFH using the standard addition method. Percentage recovery investigation was evaluated by over spotting the known amounts of EFH (480, 600, and $720 \mathrm{ng} / \mathrm{band}$ ) to the preanalyzed sample solution, and the results were reexamined by the NP-HPTLC method. The amount of $\mathrm{EFH}$ was determined from assessing the peak areas and by keeping these values to the calibration curve equation.

\section{Precision}

Precision was studied with respective to intra-day and inter-day precisions using three different concentrations of the calibration curve of EFH and was appraised in terms of \% RSD. Intra-day precision was estimated by assessing the sample solutions of EFH (900, 1200, and $1500 \mathrm{ng} /$ band) at different time intervals on the same day. Inter-day precision was estimated by assessing the sample solution of EFH (900, 1200, and $1500 \mathrm{ng} / \mathrm{band}$ ) for three consecutive days according to $\mathrm{ICH}$ guidelines. The peak area values found have been used to estimate the values of mean, standard deviations (SD), and \% RSD. Repeatability was studied at a concentration of (900 ng/band) of EFH using six times.

\section{Sensitivity}

The sensitivity of the NP-HPTLC method was calculated in terms of LOD and LOQ. The sigma method was employed for LOD and LOQ. The sigma method is based upon the slope of the calibration plot and SD of the responses. The LOD and LOQ were calculated as 3 and 10 times the noise level. The LOD and LOQ for the NP-HPTLC method were computed from the formula $\mathrm{LOD}=3.3 \times \sigma / S$ and LOQ $=10 \times \sigma / S$, where, $\sigma=$ stand ard deviation of the linearity plot and $S=$ mean slope of the linearity plot. A series of sample solutions of EFH (300-800 ng/band) were spotted on the NP-TLC plates and analyzed to appraise LOD and LOQ.

\section{Robustness and ruggedness}

The slight changes in the detection wavelength $(\mathrm{nm})$, volume of mobile phase $(\mathrm{mL})$, and activation of plate (min) were made, and the impacts on the responses were studied. Robustness experiment was evaluated using the (1500 ng/band) concentration of EFH, and the mean, $\mathrm{SD}$, and \% RSD values for peak area were measured. Ruggedness procedure was executed by two different analysts within similar experimental and environmental conditions. Ruggedness experiment was assessed using the concentration of $1500 \mathrm{ng} / \mathrm{band}$.

\section{Applicability of HPTLC method for analysis of pharmaceutical preparation}

To determination of EFH in pharmaceutical dosage form with high sensitivity and selectivity, ten Efnocar-40 tablets were weighed accurately and finely powdered in a mortar. A tablet-powdered weight equivalent to $40 \mathrm{mg}$ of EFH was transferred into clean and dry $100 \mathrm{~mL}$ of volumetric flask. The powder of EFH was dissolved in $50 \mathrm{~mL}$ of methanol using manual shaking for $2 \mathrm{~min}$ and subjected for sonication for about $20 \mathrm{~min}$. The solution was filtered through $0.45 \mu \mathrm{m}$ filter paper (Millifilter, Milford, MA, USA) and the volume was made up to the mark with the same solvent to obtain the concentration of $400 \mu \mathrm{g} / \mathrm{mL}$. From the resulting solution, appropriate 
volume was taken and diluted with methanol; the final concentration of EFH was $60 \mu \mathrm{g} / \mathrm{mL}$. From this, $10 \mu \mathrm{L}$ sample solution was spotted on NP-TLC plates using Linomat 5 applicator to get the concentration of $600 \mathrm{ng} /$ band and analyzed as per the "Chromatographic procedure" section. The area of the peak was estimated to calculate the $\%$ amount found.

\section{Results and discussion}

\section{Stability of standard solution}

To verify the stability of the solution, the stock standard solution was analyzed for about a week when it was stored at room temperature $\left(28 \pm 2{ }^{\circ} \mathrm{C}\right)$ and refrigerated at $4{ }^{\circ} \mathrm{C}$ for 1 week. The results were analyzed using checking the peak areas during this phase, and it was noted that there was no significant difference. The solution was wherefore stable.

\section{Optimization of mobile phase composition}

The selection and optimization mobile phase is a crucial step in TLC method development because it ultimately affects the quality of separation (Shewiyo et al. 2012). The selection of the effective mobile phase system for EFH analysis was taken into consideration and was studied on and based on "trial and error" basis. At the beginning, a single solvent such as $n$-hexane and ethyl acetate was selected; it was pointed out that EFH stayed as it is on the plate without any movement on taking $n$-hexane and ethyl acetate. Hence, the mixture of mobile phase system and ratio were assessed like $n$-hexane to ethyl acetate, $n$-hexane to methanol, ethyl acetate to methanol, and ethyl acetate to dichloromethane. In the first two systems, EFH remained as it is without any movement, while it is coeluted within the third system. The movement of EFH was observed in the mixture of ethyl acetate and dichloromethane with acceptable $\mathrm{R}_{f}$ value, but tailing was observed. Therefore, to decrease the tailing effect, the few drops of triethylamine were added on the basis of pKa of EFH (strongest basic- 2.33). Here, the triethylamine reduced the tailing and gets better the sharpness of the spot. At last, the good results were obtained using a solvent system consisting of ethyl acetate to dichloromethane to triethylamine in ratio (3:2:0.5 v/v) which gave an excellent compact band of EFH. Hence, this solvent system was considered for screening and optimization.

\section{Screening of significant independent variables affecting the peak area and retention factor by Plackett-Burman design}

The effect of the above six factors taken into consideration in the proposed work on peak area and $\mathrm{R}_{f}$ was statistically studied using PBD. The result of the study revealed that the impact of saturation time and development distance have a positive influence ( $p$ value $<0.05)$ on peak area, and the effect of wavelength, saturation time, volume of DCM, volume of triethylamine, development distance, and activation of plate has negative influence ( $p$ value > 0.05 ) on the $R_{f}$. Consequently, the factors having more than $95 \%$ confidence level were taken into account, and hence, the saturation time and development distance were selected for the further optimization stage and their influence on peak area was observed. The statistical results of screening for significant factors are shown in Table 4. The first-order polynomial model equation for peak area $\left(Y_{1}\right)$ and retention factor $\left(Y_{2}\right)$ can be written as:

$$
\begin{aligned}
Y_{1} & =-21,463+42.1 \text { (wavelength })-153.4(\text { saturation time }) \\
& -634 \text { volume of DCM }+852(\text { volume of triethylamine }) \\
& +277.0(\text { development distance })-70 \text { (activation of plate) }
\end{aligned}
$$

$$
\begin{aligned}
Y_{2} & =0.07+0.00444(\text { wavelength })+0.00200(\text { saturation time }) \\
& -0.0300(\text { volume of DCM })+0.117(\text { volume of triethylamine }) \\
& -0.00633(\text { development distance })-0.0200 \text { (activation of plate })
\end{aligned}
$$

The coefficient of determination $\left(R^{2}\right)$ value of $87.77 \%$ and $47.57 \%$, respectively, for peak area and retention factor indicated that up to $87.77 \%$ and $47.57 \%$ variability in peak area and retention factor could be estimated. Experimental data was statistically analyzed by $F$ test for ANOVA and the results are depicted in Table 5. The model $F$ value of 5.98 for peak area signifies that the model was significant (relationship between the response and independent variables); it means that independent variables in the proposed model improve the fit. While for retention factor, the $F$ value is 0.76 indicating that there is no relationship between the response and independent variables. The significance of each independent variable was checked using the probability value, and hence, $p$ value $<0.05$ implies a significance of each factor. Figure 2 illustrates Pareto charts of the standardized effects for responses. According to results obtained from ANOVA, the development distance and saturation time have been identified as important independent variables that only influence the peak area and were taken into consideration for further studies.

\section{Optimization of thin-layer chromatographic conditions by face-centered CCD and RSM}

The significant independent variables were identified from the PBD, i.e., development distance $\left(X_{1}\right)$ and saturation time $\left(X_{2}\right)$ selected for further optimization of chromatographic condition. Likewise, the low, middle, and high levels of corresponding independent variables for the face-centered $\operatorname{CCD}(-1,0$, and +1$)$ were estimated 
Table 4 Plackett-Burman design for statistical analysis and effect of independent variables on peak area and retention factor

\begin{tabular}{|c|c|c|c|c|c|}
\hline Factors & Effect & Coefficient & Standard error coefficient & $T$ value & $p$ value \\
\hline \multicolumn{6}{|l|}{ Peak area } \\
\hline Constant & - & 6663 & 273 & 24.41 & 0.000 \\
\hline Wavelength & 253 & 126 & 273 & 0.46 & 0.663 \\
\hline Saturation time & -1534 & -767 & 273 & -2.81 & 0.038 \\
\hline Volume of DCM & -634 & -317 & 273 & -1.16 & 0.298 \\
\hline Volume of triethylamine & 341 & 170 & 273 & 0.62 & 0.560 \\
\hline Development distance & 2770 & 1385 & 273 & 5.08 & 0.004 \\
\hline Activation of plate & -281 & -141 & 273 & -0.52 & 0.628 \\
\hline \multicolumn{6}{|l|}{ Retention factor } \\
\hline Constant & - & 0.5133 & 0.0284 & 18.10 & 0.000 \\
\hline Wavelength & 0.0267 & 0.0133 & 0.0284 & 0.47 & 0.658 \\
\hline Saturation time & 0.0200 & 0.0100 & 0.0284 & 0.35 & 0.739 \\
\hline Volume of DCM & -0.0300 & -0.0150 & 0.0284 & -0.53 & 0.620 \\
\hline Volume of triethylamine & 0.0467 & 0.0233 & 0.0284 & 0.82 & 0.448 \\
\hline Development distance & -0.0633 & -0.0317 & 0.0284 & -1.12 & 0.315 \\
\hline Activation of plate & -0.0800 & -0.0400 & 0.0284 & -1.41 & 0.218 \\
\hline
\end{tabular}

Table 5 Analysis of variance for peak area and retention factor using Plackett-Burman design

\begin{tabular}{|c|c|c|c|c|c|}
\hline Source & DF & Adj. SS & Adj. MS & $F$ value & $p$ value \\
\hline \multicolumn{6}{|l|}{ Peak area } \\
\hline Model & 6 & $3,2070,985$ & $5,345,164$ & 5.98 & 0.034 \\
\hline Linear & 6 & $32,070,985$ & $5,345,164$ & 5.98 & 0.034 \\
\hline Wavelength & 1 & 191,774 & 191,774 & 0.21 & 0.663 \\
\hline Saturation time & 1 & $7,061,677$ & $7,061,677$ & 7.90 & 0.038 \\
\hline Volume of DCM & 1 & $1,206,350$ & $1,206,350$ & 1.35 & 0.298 \\
\hline Volume of triethylamine & 1 & 348,509 & 348,509 & 0.39 & 0.560 \\
\hline Development distance & 1 & $23,025,404$ & $23,025,404$ & 25.76 & 0.004 \\
\hline Activation of plate & 1 & 237,271 & 237,271 & 0.27 & 0.628 \\
\hline Error & 5 & $4,469,113$ & 893,823 & & \\
\hline Total & 11 & $36,540,098$ & & & \\
\hline \multicolumn{6}{|l|}{ Retention factor } \\
\hline Model & 6 & 0.043800 & 0.007300 & 0.76 & 0.633 \\
\hline Linear & 6 & 0.043800 & 0.007300 & 0.76 & 0.633 \\
\hline Wavelength & 1 & 0.002133 & 0.002133 & 0.22 & 0.658 \\
\hline Saturation time & 1 & 0.001200 & 0.001200 & 0.12 & 0.739 \\
\hline Volume of DCM & 1 & 0.002700 & 0.002700 & 0.28 & 0.620 \\
\hline Volume of triethylamine & 1 & 0.006533 & 0.006533 & 0.68 & 0.448 \\
\hline Development distance & 1 & 0.012033 & 0.012033 & 1.25 & 0.315 \\
\hline Activation of plate & 1 & 0.019200 & 0.019200 & 1.99 & 0.218 \\
\hline Error & 5 & 0.048267 & 0.009653 & & \\
\hline Total & 11 & 0.092067 & & & \\
\hline
\end{tabular}



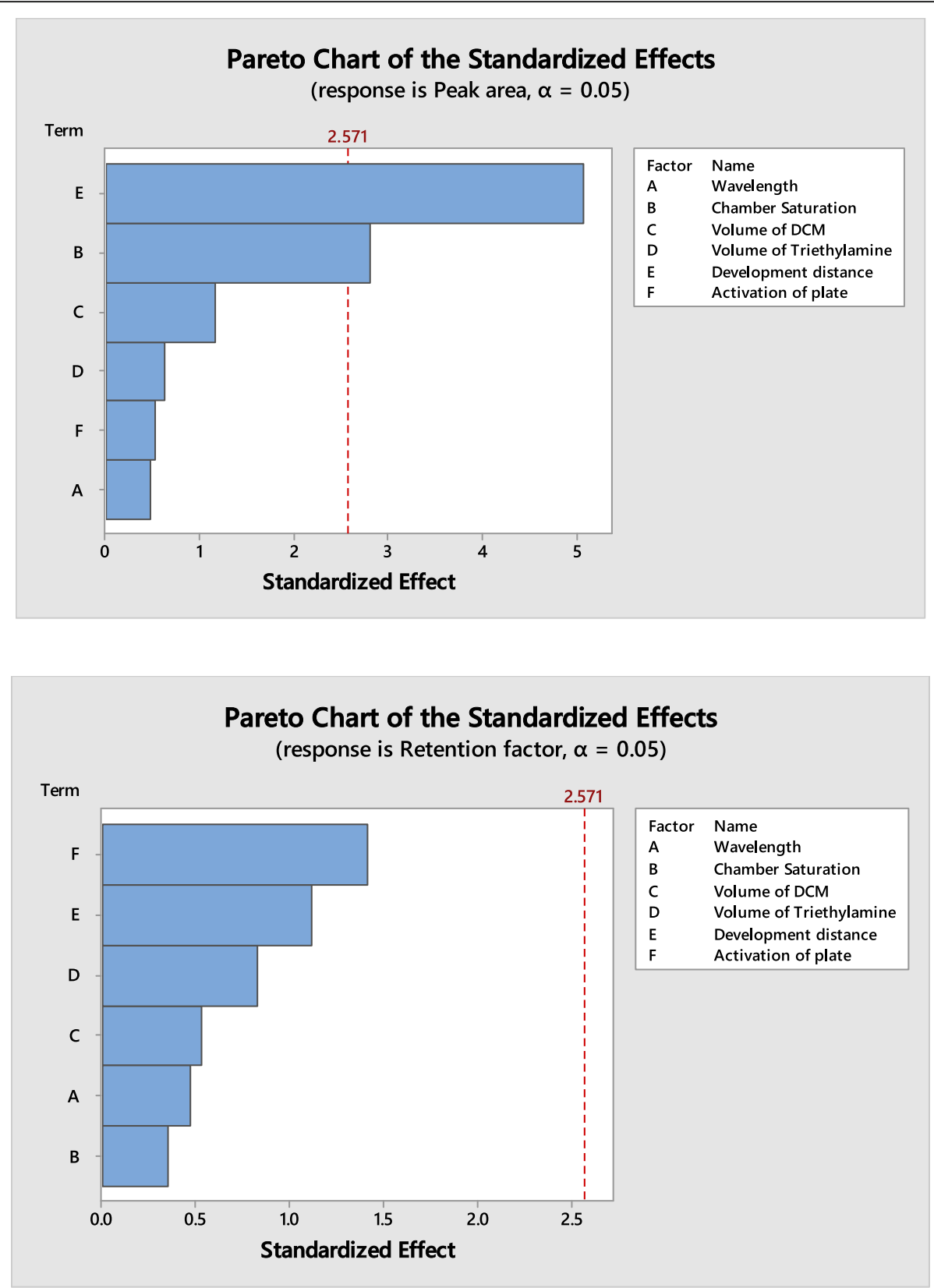

Fig. 2 Pareto chart of the standardized effects for peak area and retention factor

as per the results obtained through screening of independent variables affecting responses, and on the basis of results obtained, peak area was selected as a dependent variable. Further, the statistical model was validated using ANOVA, and analysis was done with Fisher's statistical analysis, $p$ value, and coefficient of determination $\left(R^{2}\right)$ which measures the goodness of fit of the regression model (Priyadharshini and Bakthavatsalam 2016). By exploring multiple regression analysis, the second order polynomial equation was generated to describe the relationship between the peak area $(Y)$ to the selected independent variables $X_{1}$ and $X_{2}$ being represented in the following expression:

$$
\begin{array}{r}
Y=+6677.54+210.32 X_{1}-693.40 X_{2}-729.18 X_{1} X_{2} \\
-215.49 X_{1}{ }^{2}-1191.18 X_{2}{ }^{2}
\end{array}
$$

where $Y$ is the peak area, $X_{1}$ development distance $(\mathrm{cm})$, and $X_{2}$ saturation time ( $\left.\mathrm{min}\right)$. By considering the ANOVA, results are shown in Table 6 . The $F$ value of 
Table 6 Face-centered CCD ANOVA results for peak area

\begin{tabular}{llllll}
\hline Source & Sum of square & Df & Mean square & $\boldsymbol{F}$ value & $\boldsymbol{p}$ value $\boldsymbol{F}$ \\
\hline Model & $1.064 \mathrm{E}+007$ & 5 & $2.129 \mathrm{E}+006$ & 41.19 & 0.0001 \\
$\boldsymbol{X}_{\mathbf{1}}$ & $2.654 \mathrm{E}+005$ & 1 & $2.654 \mathrm{E}+005$ & 5.14 & 0.0578 \\
$\boldsymbol{X}_{\mathbf{2}}$ & $2.885 \mathrm{E}+006$ & 1 & $2.885 \mathrm{E}+006$ & 55.83 & 0.0001 \\
$\boldsymbol{X}_{\mathbf{1}} \boldsymbol{X}_{\mathbf{2}}$ & $2.127 \mathrm{E}+006$ & 1 & $2.127 \mathrm{E}+006$ & 41.16 & 0.0004 \\
$\boldsymbol{X}_{\mathbf{1}}{ }^{2}$ & $1.283 \mathrm{E}+005$ & 1 & $1.283 \mathrm{E}+005$ & 2.48 & 0.1592 \\
$\boldsymbol{X}_{\mathbf{2}}{ }^{2}$ & $3.919 \mathrm{E}+006$ & 1 & $3.919 \mathrm{E}+006$ & 74.84 & 0.0001 \\
Residual & $3.617 \mathrm{E}+005$ & 7 & 51674.84 & & \\
Lack of fit & $3.263 \mathrm{E}+005$ & 3 & $1.088 \mathrm{E}+005$ & 12.29 & 0.0174 \\
Pure error & 35393.43 & 4 & 8848.36 & & \\
Total & $1.100 \mathrm{E}+007$ & 12 & & & \\
\hline
\end{tabular}

Df Degrees of freedom

the model was 41.19 , lack of fit $F$ value 12.29 , and the value of $p$ value (Prob $>F$ ) 0.0001, implying that the established model was significant. The $R^{2}$ was 0.9671 which is suitable for peak area and indicating excellent agreement between the predicted values. The "Pred R-Squared" of 0.7875 is in reasonable agreement with the "Adj R-Squared" of 0.9437.

The mutual interaction of each independent variable and the effect resulting from their interaction are calculated using a graphical representation of the regression model presented in Fig. 3. Frequently, the 3D response surface plots were established by plotting the dependent variable versus two of the independent variable, while the remaining variables were kept constant at an optimal level (Dinç-Zor et al. 2020). Figure 3 depicted the relationship between peak area, and two independent variables can be observed in this figure, which demonstrates that the maximum peak area could be acquired while the development distance was high $(+1)$ and saturation time was low $(-1)$. Finally, the optimum peak area was chosen from the design technique by a graphical optimization trade-off process achieved from the overlay plot (Fig. 4). The optimized value of independent variables that will give maximum peak area was the development distance $(8.5 \mathrm{~cm})$ and saturation time $(17 \mathrm{~min})$. Figure 5 depicts the chromatogram of EFH developed in the optimized chromatographic conditions was optimized from face-centered CCD and RSM. The optimized chromatographic conditions gave excellent separation of EFH with $\mathrm{R}_{f}$ of $0.35 \pm 0.25$ with maximum peak area.

\section{Linearity studies}

The proposed method shows an excellent relationship between the EFH concentration and peak areas in the range of $300-1800 \mathrm{ng} / \mathrm{band}$ for EFH. The calibration curve was very linear well and indicated a high correlation coefficient $\left(r^{2}=0.999\right)$ with a low intercept value (506.5) and the relative standard deviation (\% RSD) for all results less than 2 .
3D overlay of HPTLC densitogram of calibration curve of EFH $300-1800$ ng/band.

\section{Validation of method}

The optimized chromatographic conditions were subsequently explored to validation for different parameters accuracy, precision, sensitivity (limit of detection and limit of quantification), robustness, ruggedness, and selectivity.

\section{Accuracy}

The accuracy of the method was investigated using the known amount EFH which is spiked into the pre-analyzed sample solution. The \% recovery was found in the range $98.57-101.40 \%$ and $0.34-0.75 \%$ for EFH. The \% recoveries and $\%$ RSD values obtained were in the range and meet the acceptance conditions for the experiment; therefore, the proposed method is correct.

\section{Precision}

The precision of the method has been examined by intraday, inter-day precision, and repeatability displayed in \% RSD of the areas of peak. Intra-day and inter-day precision were achieved by executing three replicates of three distinct sample solutions of EFH (900, 1200, and $1500 \mathrm{ng} / \mathrm{band})$ and repeatability using the EFH concentration of $(900 \mathrm{ng} /$ band). The established method shows excellent precision and the \% RSD for intra-day and inter-day precision was between $0.41-1.54 \%$ and $1.14-1.66 \%$ and for repeatability $0.65 \%$, indicating that the proposed method is precise.

\section{Sensitivity}

The LOD and LOQ were calculated using the sigma method. Within optimized conditions, the LOD and LOQ were found to be $10.41 \mathrm{ng}$ and $31.57 \mathrm{ng}$. This shows that the proposed method could be accurately and precisely determined the nanogram quantity of analyte that exhibits the sensitivity of the method.

\section{Robustness and ruggedness}

The factors selected for this experiment were the detection wavelength $(\mathrm{nm})$, volume of mobile phase $(\mathrm{mL})$, and activation of plate (min). The impact of each factor on responses was assessed. The results of the robustness experiment showed that the \% RSD values of less than $2 \%$ were obtained when the minor but deliberate changes in the parameters were initiated. It may therefore be would suggest that this proposed method is robust. The proposed method proved to be rugged when the experiment was carried out using a concentration of $1500 \mathrm{ng} /$ band by two different analysts under similar experimental and environmental conditions. The results of the experiment show that the $\%$ RSD value was less than $2 \%$. 


\section{Design-Expert@ Software}

Peak Area
$\square 6965.74$

4156.69

X1 = A: Development Distance X2 = B: Saturation time

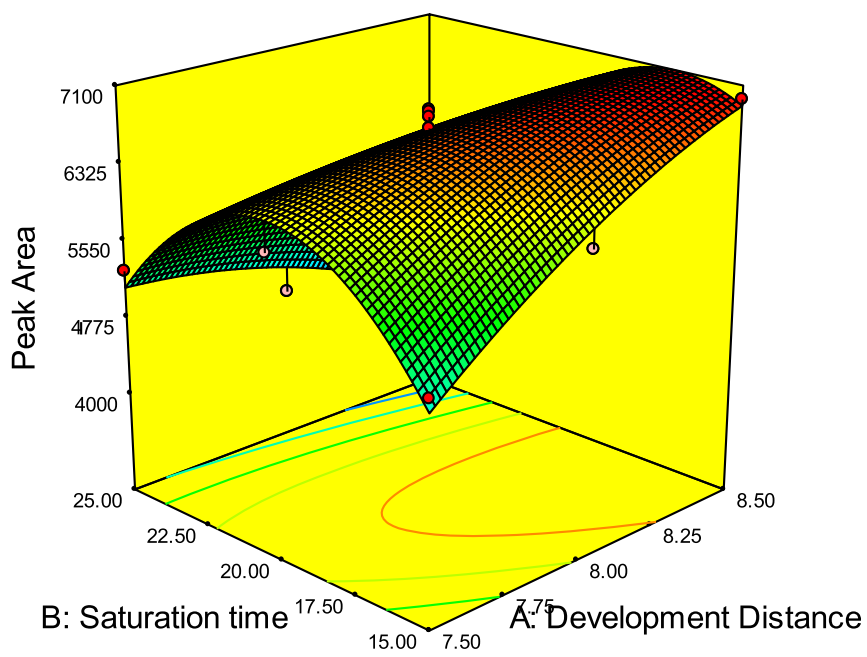

Design-Expert@ Software
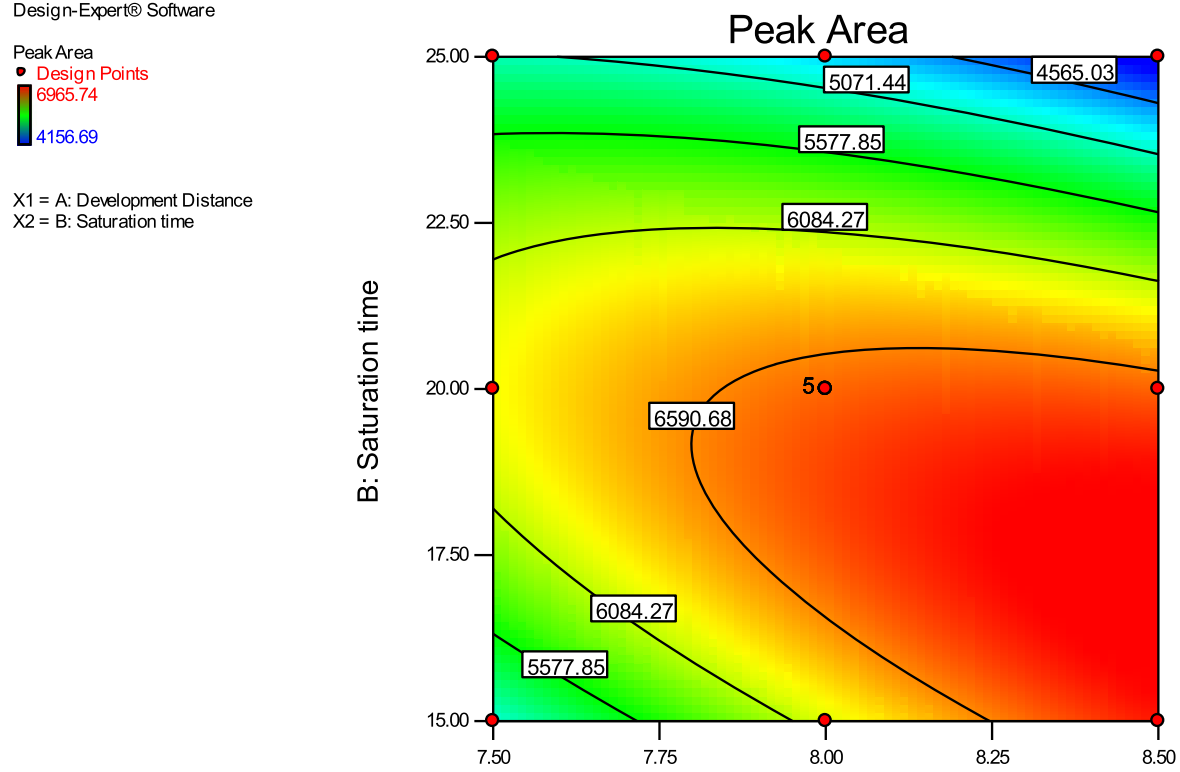

$\mathrm{X} 1=\mathrm{A}$ : Development Distance $\mathrm{X} 2=\mathrm{B} \cdot$ Saturation time

\section{A: Development Distance}

Fig. 3 DD response surface plots and counter plots demonstating the relationship between the development distance and saturation time

\section{Specificity}

Specificity is the ability of the proposed analytical method to evaluate the analyte present in the sample formulation. The peak-purity spectrum of EFH was estimated by correlating the spectra of EFH standard and EFH extracted from the Efnocar-40 tablets shows good resolution and a dense band at $R_{f}$ of $0.35 \pm 0.25$ was at the same $R_{f}$ standard. The peak purity of EFH in Efnocar-40 tablets was studied by comparing the spectra at the peak-start $(S)$, peakapex $(A)$, and at the end of peak. The correlation within these spectra means that the purity of the $\mathrm{EFH}$ (correlation $r(S, M)=0.9998, r(M, E)=$ 0.9997).

\section{Analysis of pharmaceutical preparation}

The proposed method was subjected to commercial Efnocar-40 tablets. The marketed preparation of EFH 


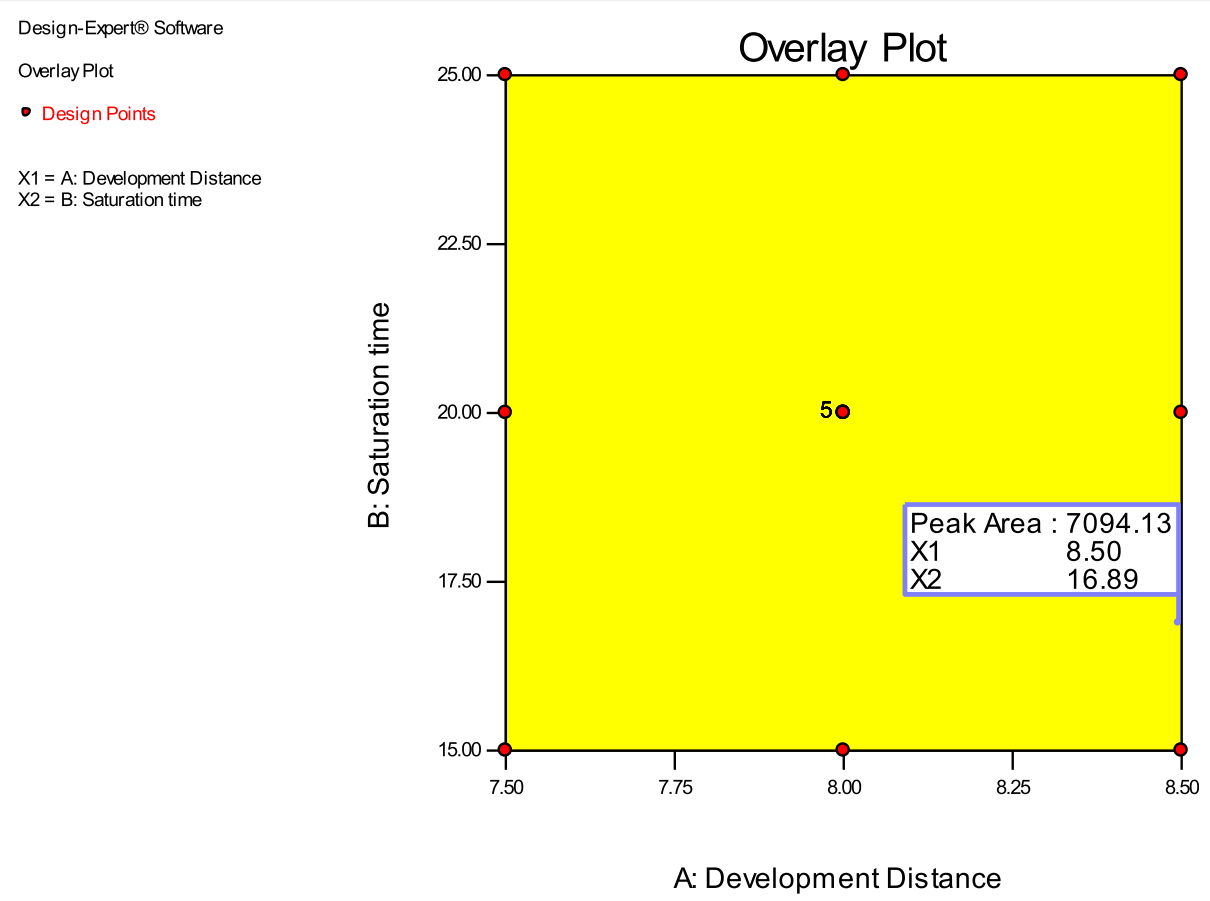

Fig. 4 Overlay plot of the face-centered CCD showing optimum chromatographic conditions

was analyzed using the established method; the amount of EFH present in Efnocar-40 tablets was $100.03 \pm 1.63 \%$. A well-resolved and compact band at $\mathrm{R}_{f}$ of $0.35 \pm 0.25$ was observed in the densitogram of EFH during analysis, and there was no excipient interference present in the marketed preparation indicating that the proposed method can be employed in routine quality control laboratories for analysis of pharmaceutical dosage form of EFH. The validation parameters are summarized in Table 7.

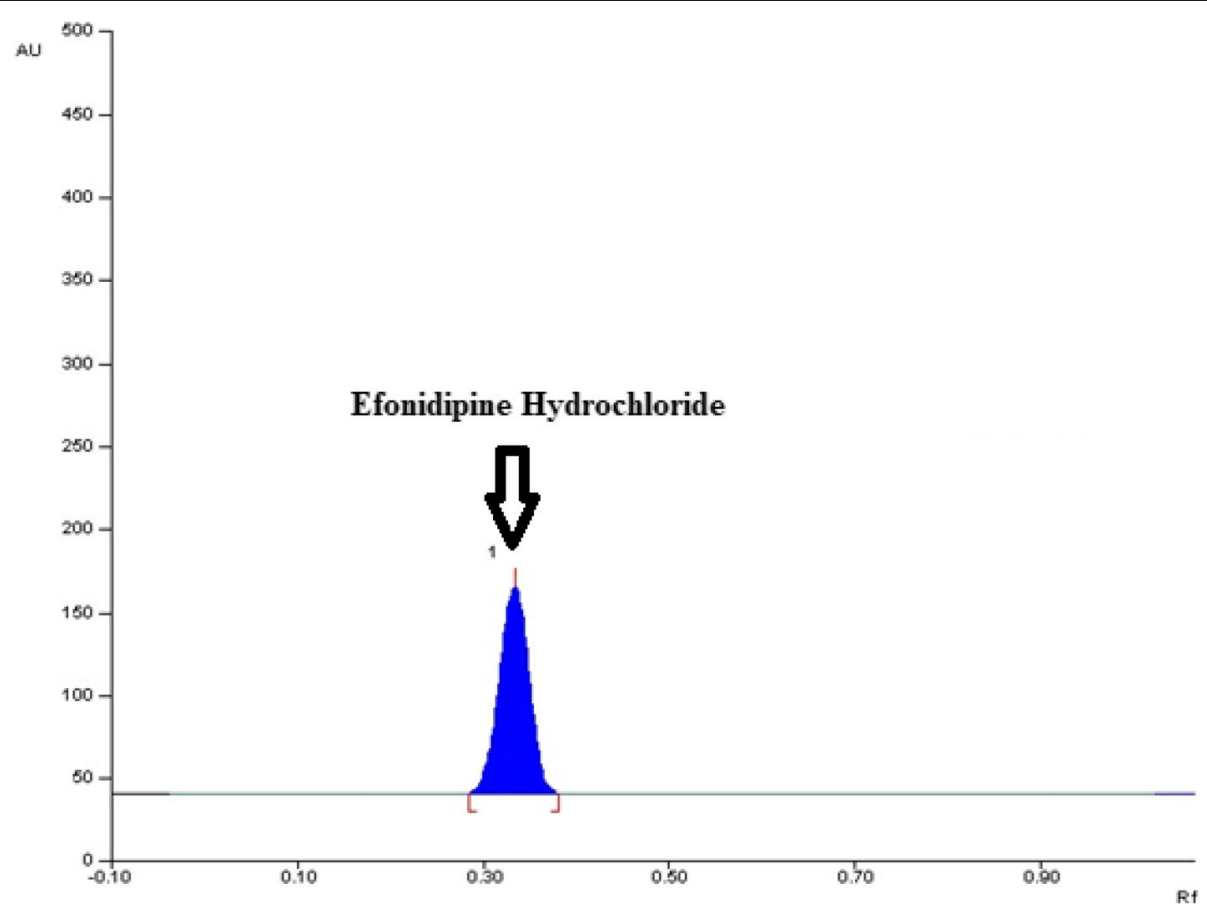

Fig. 5 Densitogram of EFH in ethyl acetate to dichloromethane to triethylamine solvent system 
Table 7 Summary of linear regression data and validation parameters of HPTLC method

\begin{tabular}{|c|c|}
\hline Parameters & HPTLC \\
\hline \multicolumn{2}{|l|}{ Linearity } \\
\hline Range (ng/band) & $300-1800$ \\
\hline Slope & 4.812 \\
\hline Intercept & 506.5 \\
\hline Correlation coefficient & 0.999 \\
\hline \multicolumn{2}{|l|}{ Accuracy } \\
\hline$\%$ recovery (\% RSD) & $98.57-101.40 \%, 0.34-0.75$ \\
\hline \multicolumn{2}{|l|}{ Precision } \\
\hline Intra-day precision $(n=3)(\%$ RSD) & $0.41-1.54$ \\
\hline Inter-day precision $(n=3)(\%$ RSD) & $1.14-1.66$ \\
\hline Repeatability $(n=6)(\%$ RSD) & 0.65 \\
\hline \multicolumn{2}{|l|}{ Sensitivity } \\
\hline Limit of detection (ng) & 10.41 \\
\hline Limit of quantification (ng) & 31.57 \\
\hline Robustness & Robust \\
\hline \multicolumn{2}{|l|}{ Ruggedness } \\
\hline Analyst-I (mean \pm SD) & $101.63 \pm 0.45$ \\
\hline Analyst-I (mean \pm SD) & $101.69 \pm 0.70$ \\
\hline Analysis of pharmaceutical preparation (mean \pm SD) & $100.03 \pm 1.63$ \\
\hline
\end{tabular}

$n$ Number of determinations

\section{Conclusion}

The proposed work describes the implementation of Plackett-Burman design and the central composite design for screening and optimization of independent variables of the HPTLC method and to achieve excellent EFH separation and detection in pure form and in commercial pharmaceutical preparation. The main objective of this work is to evaluate significant independent variables that affect the EFH peak area and retention factor and to get the maximum peak area and appropriate retention factor. Among six independent variables, development distance and saturation time as the significant independent variables affecting the EFH peak area.

Further, central composite design and response surface methodology were subjected for the optimization of development distance and saturation time. The results of experimental designs showed that a small change in development distance and saturation time had a direct effect on peak area of EFH. Thus, it is necessary to pay special attention to the precise supervision of these two independent variables during the optimization of chromatographic conditions. Moreover, validation of accuracy, precision, sensitivity, robustness, ruggedness, and specificity was demonstrated to be suitable for routine analysis of EFH in the pharmaceutical matrix. The LOD and LOQ values were $10.41 \mathrm{ng}$ and $31.57 \mathrm{ng}$ experimentally detected and quantified for EFH making the method sensitive due to the nanogram quantity of drug accurately and precisely determined. Hence, it has been accomplished that the established method is simple, sensitive, and specific for quantification EFH in bulk and pharmaceutical formulation.

\footnotetext{
Acknowledgements

The authors are thankful to Zuventus Healthcare Ltd. Mumbai for providing EFH as a gift sample and Principal of R. C. Patel Institute of Pharmaceutical Education and Research, Shirpur, India, for providing laboratory facilities necessary to carry out the proposed work.
}

Authors' contributions

Suraj Chaudhari executed the statistical experimental design and method development and validation work. Atul Shirkhedkar organized a preliminary draft of the article. The authors read and approved the final manuscript.

Funding

Not applicable

Availability of data and materials Not applicable

Competing interests

Authors declare that they have no competing interests.

Received: 18 April 2020 Accepted: 23 October 2020

Published online: 05 November 2020

\section{References}

Ahuja SK, Ferreira GM, Moreira AR. Application of Plackett-Burman design and response surface methodology to achieve exponential growth for aggregated shipworm bacterium. Biotechnol Bioeng. 2004;85:666-75. https:// doi.org/10.1002/bit.10880.

Cavazzuti M. Optimization methods: from theory to design. Berlin Heidelber: Springer; 2013. 
Dinç-Zor ş, Dönmez ÖA, Aşçı B, Pingo E. Chemometric optimization of an HPLC method for the simultaneous analysis of a multi component drug product by the help of central composite design. Microchem J. 2020;152:104322. https://doi.org/10.1016/j.microc.2019.104322.

Imam SS, Aqil M, Akhtar M, Sultana Y, Ali A. Optimization of mobile phase by 32mixture design for the validation and quantification of risperidone in bulk and pharmaceutical formulations using RP-HPLC. Anal Methods. 2014;6:2828. https://doi.org/10.1039/C3AY41562G.

International Conference of Harmonisation. Q2 (R1), validation of analytical procedures: text and methodology. Geneva: International Conference on Harmonization; 2005. p. 11-2.

Kumar A, Shoni SK, Dahiya M, Kumar R, Yadav AK. Development and validation of liquid chromatography (RP-HPLC) methodology for estimation of efonidipine HCl ethanolate (EFD). Pharm Anal Acta. 2017;8:547. https://doi.org/10.4172/ 2153-2435.1000547.

Liu M, Deng M, Zhang D, Wang X, Ma J, Zhao H, et al. A chiral LC-MS/MS method for the stereospecific determination of efonidipine in human plasma. J Pharm Biomed Anal. 2016;122:35-41. https://doi.org/10.1016/j.jpba.2016.01.039.

Liu M, Zhao H, Tong Y, Zhang D, Wang X, Zhang L, et al. Determination of efonidipine in human plasma by LC-MS/MS for pharmacokinetic applications. J Pharm Biomed Anal. 2015;103:1-6. https://doi.org/10.1016/j.jpba.2014.11.001.

Masuda Y, Miyajima M, Shudo C, Tanaka S, Shigenobu K, Kasuya Y. Cardiovascular selectivity of 1, 4-dihydropyridine derivatives, efonidipine (NZ-105), nicardipine and structure related compounds in isolated Guinea-pig tissues. Gen Pharmacol The Vasc Syst. 1995;26:339-45. https://doi.org/10.1016/03063623(94)00187-R.

Masumiya H, Matsuda T, Tanaka Y, Tanaka H, Shigenobu K. Possible requirement of phosphonate moiety for efonidipine effects on the sino-atrial node action potential. Life Sci. 2000;66:239-44. https://doi.org/10.1016/S0024-3205(00)00475-6.

Masumiya $\mathrm{H}$, Tanaka $\mathrm{H}$, Shigenobu K. Effects of $\mathrm{Ca} 2+$ channel antagonists on sinus node: prolongation of late phase 4 depolarization by efonidipine. Eur J Pharmacol. 1997;335:15-21. https://doi.org/10.1016/S0014-2999(97)01150-3.

Müller ALH, de Oliveira JA, Prestes OD, Adaime MB, Zanella R. Design of experiments and method development. In: Solid-phase extraction. Amsterdam: Elsevier; 2020. p. 589-608.

Naveena BJ, Altaf M, Bhadriah K, Reddy G. Selection of medium components by Plackett-Burman design for production of $\mathrm{L}(+)$ lactic acid by lactobacillus amylophilus GV6 in SSF using wheat bran. Bioresour Technol. 2005;96:48590. https://doi.org/10.1016/j.biortech.2004.05.020.

Priyadharshini SD, Bakthavatsalam AK. Optimization of phenol degradation by the microalga Chlorella pyrenoidosa using Plackett-Burman design and response surface methodology. Bioresour Technol. 2016;207:150-6. https://doi.org/10. 1016/j.biortech.2016.01.138.

Shewiyo DH, Kaale EAKK, Risha PG, Dejaegher B, Smeyers-Verbeke J, Vander Heyden Y. HPTLC methods to assay active ingredients in pharmaceutical formulations: a review of the method development and validation steps. J Pharm Biomed Anal. 2012;66:11-23. https://doi.org/10.1016/j.jpba.2012.03.034.

Tanaka H, Shigenobu K. Efonidipine hydrochloride: a dual blocker of L-and T-type $\mathrm{Ca}^{2+}$ channels. Cardiovasc Drug Rev. 2002;20:81-92. https://doi.org/10.1111/j. 1527-3466.2002.tb00084.x

Tauler R, Walczak B, Brown SD. Comprehensive chemometrics: chemical and biochemical data analysis. Amsterdam: Elsevier; 2009.

Vanaja K, Shobha Rani RH. Design of experiments: concept and applications of Plackett Burman design. Clin Res Regul Aff. 2007;24:1-23. https://doi.org/10. 1080/10601330701220520

Varshosaz J, Ghaffari S, Khoshayand MR, Atyabi F, Azarmi S, Kobarfard F. Development and optimization of solid lipid nanoparticles of amikacin by central composite design. J Liposome Res. 2010;20:97-104. https://doi.org/10. 3109/08982100903103904

\section{Publisher's Note}

Springer Nature remains neutral with regard to jurisdictional claims in published maps and institutional affiliations. 